\title{
SoTL's Impact on Teaching Goals: A Case Study from a Regional University
}

\author{
Kelley Shaffer, $\mathrm{PhD}$ \\ Director, Center for Instructional Innovation \\ Tarleton State University \\ James E. Gentry, EdD \\ Professor, Department of Curriculum and Instruction \\ Tarleton State University \\ Sarah Maben, PhD \\ Department of Communication Studies \\ Tarleton State University
}

This study reviewed the impact of a Scholarship of Teaching and Learning (SoTL) program offered at a university. While there is a plethora of literature available that addresses the impact on scholars' teaching methods and classroom research, few publications address SoTL's impact on teaching goals. Twelve faculty scholars participated in the cohort-based program and completed the Angelo and Cross' (1993a) Teaching Goals Inventory (TGI) before and after participation in SoTL. Statistically significant increases with medium to large effect were noted for two TGI clusters. Faculty scholars' quotes provided evidence of how their practice changed after this SoTL program.

The Scholarship of Teaching and Learning, or SoTL, is a solid method of classroom research that can be traced back to Ernest Boyer's seminal book Scholarship Reconsidered (1990). As the years have passed and SoTL has grown in acceptance and spread to universities around the globe, more scholars have refined the definition and extolled its many benefits. Hodges (2013) suggested that SoTL is a mindset of "questioning old assumptions about what teaching entails and how our students learn, gathering and examining evidence of the effects of our approaches, and reflecting on and sharing insights gained" (p. 72). While the many benefits of SoTL are wide and varied, the main goal of SoTL is improving student learning. The skills that faculty develop through SoTL (reflection, collaboration, and collegiality) apply to research and service efforts as well (Case, 2013). Opening the dialogue with other colleagues about teaching benefits the academic community; shared SoTL findings lead to new teaching approaches (Dickson \& Treml, 2013).

While most scholars agree SoTL has an impact on student learning, there is sparse scholarly activity about the impact that the Scholarship of Teaching and Learning has on scholarly participants' teaching goals. Stevenson and Harris (2014) said instructor teaching characteristics and differences are rarely mentioned. However, K.P. Cross (2005) touched on this idea by saying that classroom research is an ongoing effort of a teacher to evaluate the "accomplishment of his or her teaching goals" (p. 10). While she wasn't directly connecting teaching goals to SoTL, classroom research is the foundation of SoTL, so we should be able to determine if SoTL has an effect on faculty teaching goals. The purpose of this study is to determine if participating in a SoTL program affects scholar participants' teaching goals. 


\section{Learning Engagement and SoTL’s Influence}

Increasing faculty engagement in SoTL benefits students. Faculty members pursue SoTL for various reasons such as enhancing learning, demonstrating teaching commitment, and supporting higher education's teaching and learning (Kenny \& Evers, 2010). SoTL also enriches scholarly research activities of faculty scholars by offering tangible insights about the impact on learners. SoTL projects exhibit various methodologies and research paradigms, from qualitative to quantitative, literature reviews to meta-analyses, experimental or descriptive; they are SoTL projects nonetheless, as long as they are systematic and public (Kern, Mettetal, Dixson, \& Morgan, 2015). With scant literature explicitly tying teaching goals to SoTL, researchers used two lines of research to build the foundation for this study: SoTL and its impact on students and professors and teaching goals and the Teaching Goals Inventory.

\section{SoTL's Impact on Students, Professors, and Institutions}

The SoTL movement has gained traction since Boyer's 1990 work. SoTL has an impact on students (Condon, Iverson, Manduca, Rutz, \& Willett, 2016; Trigwell, 2013), faculty, and universities (Cox, 2004; Voelker \& Martin, 2013). Universities are building support and spreading the SoTL message in a variety of ways. Faculty learning communities and cohorts are one way to add to the army of SoTL advocates on a campus. In a semester or two, faculty members learn how to conduct SoTL projects and add another research stream to their individual agendas and raise awareness about SoTL department by department. Faculty SoTL development initiatives influence teaching practices (Condon et al., 2016), and universities are investing in SoTL.

Academic write-ups about university SoTL programs report generally favorable outcomes. For example, the University of Wisconsin System found that $96 \%$ of participants $(n=130)$ in its 11-year SoTL history reported a positive impact from its program (Voelker \& Martin, 2013). Sixty-two percent of participants published SoTLrelated works. Sixty-six percent of the SoTL projects at Southeast Missouri State showed enhanced student learning (100 courses and 4,500 students affected) (Waterman et al., 2010). And lastly, Miami University uses faculty learning communities (FLCs) to foster a community-based approached to campus issues, including SoTL (Cox, 2004). Miami University's faculty learning communities (including SoTL) saw student learning increased as a result of the teaching projects, and faculty reported changes in student learning due to improved faculty attitude about teaching (Cox, 2004).

SoTL's benefits extend beyond faculty development programs - students benefit as well (Condon et al., 2016; Trigwell, 2013). Trigwell (2013) found support for connections between teachers using certain aspects of SoTL and the likelihood of improving their students' learning. SoTL requires faculty to question student learning and investigate it for the benefit of the individual classroom and the advancement of teaching and learning on a larger scale (Condon et al., 2016; Hutchings \& Shulman, 1999). The SoTL impact may begin as a way to improve one class, but what a faculty 
member discovers can inform their future classes and the academy as a whole (Marketti, VanDerZanden, \& Leptien, 2015). For example, Marcketti, VanDerZanden, and Leptien (2015) found faculty continuing SoTL work for benefits beyond promotion and tenure. They looked at the impact SoTL had on the "SoTL champions" on one university campus. Professors who engaged in SoTL reported continuing their SoTL research even after achieving tenure or a promotion because of 1) the synergy it creates between research and teaching, 2) the additional community SoTL created - moving outside of traditional silos, and 3) an extended individual prominence. One respondent to the qualitative study said SoTL made his position "feel like one job instead of three different jobs" (p. 7). Another institution reported similar faculty perceived benefits after interviewing an inaugural SoTL cohort; participants expanded disciple-specific research agendas to include SoTL projects (Garza, Shaffer, Gentry, Maben, \& McGahan, 2014, p. 11).

Faculty committed to SoTL early in their careers will increase their commitment to SoTL throughout their careers (Myers, 2008). Likewise, Auten and Twigg (2015) call for using SoTL as a way to teach graduate students and future professors about teaching; they said it would allow future teachers to read their classrooms and "locate themselves as learners and colleagues" (Auten \& Twigg, 2015, p. 11). In essence, SoTL becomes part of beginning faculty members' identity and part of their core professional values (Nicholls, 2004). Simmons et al. (2013) cautioned that while maintaining both a SoTL and discipline-specific research agendas could be troublesome, the reward could be transformative.

These studies capture the impact of SoTL on students, professors and institutions, but they do not mention how or if SoTL programs, a type of professional development, impact a professor's teaching goals. Using the Teaching Goals Inventory, this study aims to provide a first effort at investigating such a connection.

\section{Teaching Goals and the Teaching Goals Inventory}

For this study, teaching goals are defined as what college faculty would like to prioritize or accomplish in their classroom, regardless of discipline. This definition aligns quite nicely with the research conducted by Angelo and Gross (1993a) when they developed the Teaching Goals Inventory to score these priorities. Why do teaching goals matter? Ortiz (2011) asserts that teaching goals are targets for student learning. To meet these goals, teachers will use

Identifying teaching goals provides insights into a teacher's classroom approach including assessment strategies, assignments, textbook selection, and objectives. methods based on their beliefs about students and student learning to meet these teaching goals (Ortiz, 2011). Teaching goals provide a framework for the teacher's course design and instructional choices (Friedrichsen \& Dana, 2005; Grossman, 1990). Identifying teaching goals provides insights into a teacher's classroom approach including assessment strategies, assignments, textbook selection, and objectives (Grossman, 1990). Teaching goals significantly impact "subsequent teaching behaviors" (Wang, Hall, Goetz, \& Frenzel, 2017, p. 101) and relate to use of learner-centered teaching methods (Richardson \& Miller, 2011). Awareness of teaching goals could help faculty members identify disconnects between what they hope to achieve in the classroom and what is actually achieved (Richardson \& Miller, 2011). 
Professors select teaching goals by focusing on learning needs of students (Albornoz Pardo, 2013). SoTL helps investigate and isolate aspects of teaching and learning. It is with this logic that we assert changes to teaching goals imply changes to course decisions.

Angelo and Cross' Teaching Goals Inventory (TGI) is a questionnaire that measures goals for one particular course. An instrument description is included in the data analysis portion of this paper. Ortiz, for example, used the TGI to measure changes in goals for pre-service math teachers. An organization for the betterment of teaching in the geosciences suggests that the TGI be used for educators developing or revising a course, constructing a teaching philosophy or undergoing curriculum review (Science Education Resource Center at Carleton College, n.d.). Stanford University suggests that the TGI can help with course focus and syllabus development by setting reasonable expectations for what goals can be accomplished in a term (Define Your Goals, 1993). In evaluating faculty learning communities, Miami University categorized its FLC learning outcomes using TGI (Cox, 2004). Johnson (1997) used TGI to compare teaching goals of faculty members at research institutions.

From the Ivy League to community colleges, universities' centers for teaching excellence or instructional innovation offer the TGI as a resource to faculty members (see Vanderbilt University Center for Teaching, 2018, or Colorado Community Colleges, 2018). Researchers selected the TGI as the instrument to measure participant pre- and post- teaching goals because of the TGI's prominence in the US and online as well as the content measured. The TGI is worded to help instructors decide on teaching goals for one particular class at a time and offers many self-scoring versions online. Participants in a SoTL program could continue to make use of the resource in future independent SoTL research projects.

\section{Study's Purpose and Rationale}

The current study focuses on the following research question: Does faculty scholars' participation in a SoTL program offered at a regional university impact the scholars' teaching goals? The purpose of which is to determine if any of the goals changed after participating in the program. Researchers hope to gain insight into the SoTL program's influence on faculty scholars' perceptions and values related to teaching. If any of the goals change, the researchers plan to delve deeper into participant interview questions for future cohorts to determine why teaching goals changed. Based on the data, researchers will also make program revisions for future SoTL experiences.

\section{Procedure}

A regional university in the southern United States launched a SoTL program with an inaugural cohort of 12 faculty scholars that represented all colleges at the university. The program consisted of five workshops held on Saturdays throughout the 16-week spring semester. Topics covered during the workshops were What is SoTL and How Do I Get Started?; Generating the Research Question \& Research Design; Navigating the IRB Process; Validity \& Reliability; Available Resources; Collecting and Analyzing Data; and Project Completion \& Presentation. The workshops were led by the Faculty Fellows, a group of five faculty representatives from the university's 
colleges and the Director of the Center for Instructional Innovation. As a pre- and postmeasure, faculty scholars completed two surveys: The Carnegie Academy for the Scholarship of Teaching and Learning (CASTL) survey (Carnegie Foundation for the Advancement of Teaching, 2004) and the Teaching Goals Inventory (TGI) (Angelo \& Cross, 1993b). Both surveys were used with permission and selected to determine if participating in a SoTL program made an impact on the faculty scholars teaching practice and teaching goals. Only the TGI survey was addressed in this study since this manuscript's focus concerned the impact of this SoTL experience on faculty's teaching goals. Researchers decided to save the CASTL survey data for a future research writing project related to evaluating this inaugural SoTL experience's impact at an institutional level.

At the conclusion of the program, faculty scholars were asked six open-ended interview questions to determine their overall perception of the SoTL program and if it made a difference with their teaching methods, goals, and research agenda. This study focuses on comparing the results of the TGI survey and two of the six interview questions: "How has the SoTL experience impacted your teaching?" and "Is there anything else you want to say?" The remaining four questions focused on program improvement and impact on the faculty scholars' research agenda and are not included in this data analysis and results. The interview questions were asked by a trained graduate assistant with no involvement in the research other than as an interviewer. Quantitative and qualitative data analysis methods were used to support the findings.

\section{The TGI Survey Instrument}

When developing the TGI, Angelo and Cross (1993a) stated that the purpose of the TGI is threefold:

(1) To help college teachers become more aware of what they want to accomplish in individual courses, (2) to help faculty locate Classroom Assessment Techniques they can adapt and use to assess how well they are achieving teaching and learning goals, and (3) to provide a starting point for discussions of teaching and learning goals among colleagues. (p. 20)

It "enables teachers to locate the assessment techniques that are most appropriate for their particular teaching goals" (Angelo \& Cross, 1993a, p. xv). The TGI is a self-scoring survey comprised of 53 goal questions, grouped into six clusters. The six clusters are:

1. Higher-Order Thinking Skills (apply learning in authentic situations),

2. Basic Academic Success Skills (memory, literacy, and computation skills),

3. Discipline-Specific Knowledge and Skills (knowledge of theoretical frameworks related to discipline),

4. Liberal Arts and Academic Values (appreciation of new ideas, citizenship responsibilities, and lifelong learning),

5. Work and Career Preparation (leadership and the development of new skills), and

6. Personal Development (responsibility for personal behavior, self-efficacy related to the discipline skills, and respect for colleagues and collaboration). (Angelo \& Cross, 1993a, p. 22) 
The Teaching Goals Inventory is widely used for professional development by colleges and universities around the globe. The full inventory can be accessed at https://fm.iowa.uiowa.edu/fmi/xsl/tgi/data entry.xsl?-db=tgi data\&-lay=Layout01\&view (University of Iowa, n.d.).

\section{Data Analysis}

For this study, TGI scores were analyzed using descriptive statistics. Fiftytwo of the 53 questions were analyzed with the responses from the pre- and post-test. The 52 goal questions were based on a Likert scale. The 53rd question of the inventory was omitted from data analysis because it is not a Likert scale question like the other 52. The $53^{\text {rd }}$ is a multiple choice question that asks respondent to rate their primary role as a teacher and is not included in the clusters (Angelo \& Cross, 1993a, p. xv). Scholars had the opportunity to select one of five ratings per prompt in each cluster. The selections were essential (E), very important (VI), important (I), unimportant (U), and not applicable (NA). Researchers assigned numeric values for analysis: $E=4, \mathrm{VI}=3$, $\mathrm{I}=2, \mathrm{U}=1, \mathrm{NA}=0$. For each scholar, a mean response score was determined for each cluster and overall for both the pre- and post-SoTL TGI survey. These scores formed interval scales to compare gains and losses using means.

Parametric paired $t$-tests comparisons were reported pre/post- per TGI cluster using means and standard deviations, respectfully (see Table 1). Effect sizes (Cohen's d) of significant results were reported as well. Since the study has a small number of participants, normality assumptions were assessed using Shapiro-Wilk tests. The paired t-test was utilized for TGI pre- and post- cluster comparisons due to the robust nature and proven accuracy of the paired t-test with small sample sizes (De Winter, 2013; Sheskin, 2011).

The interview questions were asked by a graduate student with no vested interest in this research project. Interviews were recorded and transcribed for analysis. Researchers individually coded key words from the written transcripts and then met as a group to compare key word coding and synthesize the data into categories/themes. By using multiple coders, the researchers were able to construct categories or themes that capture recurring patterns across the data (Merriam, 2009). Several themes emerged. Those that did not pertain to teaching goals were not included in the results.

\section{Results}

The grouping of the TGI goal questions into clusters produced interval-scale measures for parametric paired $t$-test comparisons. The difference scores for all preand post- TGI interval-scale measures were normally distributed, as assessed by Shapiro-Wilk's tests. Two significant differences were discovered for faculty scholars among the six cluster parametric mean comparisons. TGI clusters IV (Liberal Arts and Academic Values) and VI (Personal Development) produced significant mean increases between pre $(M=2.23, S D=.84 / M=2.75, S D=.67)$ and post $(M=2.48$, $S D=.77 / M=3.07, S D=.70$ ) measures, respectively (See Table 1). Pre- and post- TGI clusters IV and VI revealed medium to large effect sizes $(d=.61)$ and $(d=.68)$, respectively. Hattie (2009) redefined effect sizes for school learning and recommended $d=.2$ (small), $d=.4$ (medium), and $d=.6$ (large). 
This study served as an initial investigation concerning the impact of this SoTL experience on faculty's teaching goals. Researchers chose to focus on the two clusters that were significantly different. However, it is important to note that most TGI clusters with the exception of TGI cluster three, Discipline-Specific Knowledge and Skills, and TGI goal five, Work and Career Preparation, revealed faculty impact mean increases from the pre- to post- SoTL experience (see Table 1).

Table 1

Results of Pre- and Post-SoTL TGI Surveys by the Six Clusters

\begin{tabular}{|c|c|c|c|c|c|c|}
\hline Cluster & Phase & Mean (SD) & t-score & $\mathrm{p}$-value & Cohen's d & $\mathrm{W} / \mathrm{p}$-value \\
\hline \multirow[t]{2}{*}{1} & Pre & $3.08(0.70)$ & \multirow{2}{*}{0.59} & \multirow{2}{*}{0.56} & \multirow{2}{*}{ na } & \multirow{2}{*}{.192} \\
\hline & Post & $3.18(0.70)$ & & & & \\
\hline \multirow[t]{2}{*}{2} & Pre & $2.68(0.84)$ & \multirow{2}{*}{0.58} & \multirow{2}{*}{0.56} & \multirow{2}{*}{ na } & \multirow{2}{*}{.541} \\
\hline & Post & $2.79(0.88)$ & & & & \\
\hline \multirow[t]{2}{*}{3} & Pre & $2.96(0.49)$ & \multirow{2}{*}{-0.34} & \multirow{2}{*}{0.73} & \multirow{2}{*}{ na } & \multirow{2}{*}{.999} \\
\hline & Post & $2.91(0.71)$ & & & & \\
\hline \multirow[t]{2}{*}{4} & Pre & $2.23(0.84)$ & \multirow{2}{*}{2.12} & \multirow{2}{*}{$0.05^{*}$} & \multirow{2}{*}{.61} & \multirow{2}{*}{.865} \\
\hline & Post & $2.48(0.77)$ & & & & \\
\hline \multirow[t]{2}{*}{5} & Pre & $3.09(0.67)$ & \multirow{2}{*}{-0.63} & \multirow{2}{*}{0.54} & \multirow{2}{*}{ na } & \multirow{2}{*}{.187} \\
\hline & Post & $2.97(0.72)$ & & & & \\
\hline \multirow[t]{2}{*}{6} & Pre & $2.75(0.67)$ & \multirow{2}{*}{2.35} & \multirow{2}{*}{$0.03^{* *}$} & \multirow{2}{*}{.68} & \multirow{2}{*}{.121} \\
\hline & Post & $3.07(0.70)$ & & & & \\
\hline
\end{tabular}

Note. ${ }^{*} p<0.10 ;{ }^{* *} p<0.05$. 1=Higher Order Thinking Skills, 2=Basic Academic Success Skills, 3=Discipline Specific Knowledge and Skills, 4=Liberal Arts and Academic Values, $5=$ Work and Career preparation, and $6=$ Personal Development. Na=not applicable. $\mathrm{W} / \mathrm{p}$-value=Shapiro-Wilk test $(\mathrm{W})$ of normality $\mathrm{p}$-values. Significant results suggest a deviation from normality with the Shapiro-Wilk tests of normality. The gray highlight displays the two mean TGI goal decreases from the pre- to postSoTL experience.

In addition to the quantitative analysis, the qualitative analysis revealed an overarching theme of transformational teaching in the interview data. As a result of participating in this program, several of the faculty scholars remarked that conducting classroom research has helped them refocus on their teaching methods and goals. Participant E learned that "being able to do research on what I'm passionate about, which is teaching, was kind of eye opening." This scholar added that going through this program made her aware of classroom research and has given her renewed focus on teaching. Participant H concurred and provided this statement: "It's definitely opened my mind to other possibilities in the way that I teach...It's given me great ideas and has made me really kind of reconsider my approach to teaching in the classroom." Participant J remarked, "It's definitely made me look at things in my classes to determine does this really impact my students? Is it impacting them in a way I want 
them to be impacted with?" Participant B remarked, “...from actually learning about how you teach and being ready to implement that back into the classroom was very important." He succinctly stated what all the others inferred, "As a learning institute and for us to be better teachers, we need to keep doing as much scholarship on teaching and learning as we can."

While the other interview questions that dealt with program improvement and research impact were not included in this analysis, their responses did contain both positive and negative (but constructive) feedback. What the researchers found during qualitative analysis was that all 12 participants reported positive perceptions on the impact to their teaching, which was reflected in the quantitative analysis.

\section{Discussion}

Based on the qualitative and quantitative analysis of the pre- and post- SoTL surveys and faculty scholars' interviews and reflection of the program, completing a SoTL program had a positive impact on two teaching clusters (i.e., TGI clusters IV and VI, Liberal Arts and Academic Values and Personal Development). Gains were noted. Since the purpose of the SoTL program is to focus on classroom research for one course, faculty scholars were asked to concentrate on the student learning outcomes (also known as course objectives) for their course and how to assess their research project. Over the course of the program, the scholars openly shared their obstacles and successes. Through these cross-discipline discussions, scholars received constructive feedback and encouragement from each other and the program leaders. After the various discussions and strategies shared in SoTL meetings relating to building responsible and independent students who have an appreciation for learning, regardless of the discipline, researchers were not surprised clusters IV and VI improved. Many of the discussions centered on preparing students to be life-long learners who find confidence because they have taken advantage of the learning opportunities provided in their various disciplines and associated classes. This is supported by purpose number three of the TGI as stated by Angelo and Cross (1993a, p 20). The learning experiences with faculty scholars within the SoTL environment influenced positive gains in TGI cluster IV (Liberal Arts and Academic Values) and VI (Personal Development). Many of the scholars' statements reflected personal growth in teaching and research, which is consistent with the literature (Poole \& Chick, 2015; Trigwell, 2013; Voelker \& Martin, 2013; West, 2013). Faculty scholar D stated, "[SoTL] changed my perspective on my teaching and maybe not be so apprehensive about making changes in my teaching style." Faculty scholar G stated, "I've gone from just being someone in front of the room throwing information out to trying to get the students more involved and making it more of an engaging environment." This research shows a positive impact on teaching goals for existing faculty after participating in formalized SoTL instruction.

Although most of the TGI clusters, including the two clusters with significant differences, revealed mean increases from the pre- to post- SoTL experience, TGI clusters three and five produced mean decreases from the faculty scholars. The SoTL experience had less impact on faculty's perception regarding TGI cluster three, delivering discipline specific knowledge, since the SoTL experience focus and activities 
center on research-based pedagogy and engaging instructional practices. Faculty may have determined the SoTL experience was a place for discovery and practice of research-based instructional strategies while their discipline specific terminal degree and educational training experiences provided the content to be delivered. "The best teachers are not always, not even usually, those teachers with the most sophisticated content knowledge. The best teachers do know their material, but they also know a lot about the process" (Weimer, 2007, p. 4). As with TGI cluster three, the mean decrease with TGI cluster five, Work and Career Preparation, may have resulted due to the faculty scholars' perceptions regarding work experience and maturity as the central experiences that prepare individuals for work and career culture. Future research projects could examine each cluster in-depth with both quantitative and qualitative methodologies to dispel speculation with inquiry based findings and results.

Ortiz (2011) maintained that teaching goals matter because they act as targets for student learning. Setting and working to fulfill teaching goals is a kind of exercise that benefits from professional development. Participating in a SoTL instructional program provides both personal and professional development. Whether by selfstudy, informal or formal instruction, those in teaching roles can develop the instructional part of their academic responsibilities. This study's findings are consistent with Trigwell, Rodriguez, and Han (2012), who found moderate evidence of positive impact on a professional development program for teaching. Their findings were consistent with other literature pointing to higher education professional development programs "changing teachers' conceptions of teaching and learning" ( $\mathrm{p}$. 507). Examples include Donnelly's (2008) study of a professional development program for educators in Ireland. Participants in her study reported multidimensional changes to their teaching, including adding new teaching strategies and approaches and altering their own beliefs about teaching and learning in higher education.

Postareff, Lindblom-Ylänne, and Nevgi (2008) argue that professional development courses for educators should focus on changing a teacher's "conceptions of teaching" rather than their techniques (p. 42). In the qualitative analysis, faculty scholars in the SoTL program described how they now thought about teaching and the value in conducting research on their instructional concepts.

A limitation of this study is the sample size from one university. The researchers plan to continue tracking the teaching goals of future cohorts of scholars to increase the participant pool size and determine if the results of this study are an anomaly or if SoTL continues to positively impact the teaching goals of scholars, which impacts how they approach course instruction (Friedrichsen \& Dana, 2005, Grossman, 1990).

\section{Implications and Future Research}

Implications for research on teaching goals and SoTL could impact individual classrooms, departments, and institutions. Bernstein (2013) called for SoTL to be an "essential and continuous investment in human capital" at every institution (p. 39). Increases in teaching goal measures can provide assessment data to foster more extensive support and funding for SoTL research. From the department level, chairs might be more willing to offer course release or other incentives so faculty members 
(and the department) would invest in SoTL and related professional development programs. Individual educators would have data to show professional development gains and value for their time for such training efforts. Looking back at the origins of SoTL thought and processes in various disciplines at the university level (Boyer, 1990), educators' ideas about teaching have been changing to include research regarding the effectiveness of teaching practices. Therefore, teaching and research are the best partners in any classroom seeking improved learning outcomes for students. In the past, research and teaching were primarily considered to be separate entities by many disciplines. Perhaps the greatest discovery for any educator may be the knowledge that research techniques provide answers to improve teaching and to determine the effectiveness of various teaching practices.

Ideas for future research include following up with SoTL scholars at intervals after the cohort program to see if they have integrated SoTL into their research agenda, and what lasting effects SoTL programs can have on professors, students, and institutions. Researchers will also explore adding the revised Approaches to Teaching Inventory (ATI) survey instrument as a pre- and post-test measure for program participants, as a way to connect this cohort to global studies. The ATI was developed

In the past, research and teaching were primarily considered to be separate entities by many disciplines. Perhaps the greatest discovery for any educator may be the knowledge that research techniques provide answers to improve teaching and to determine the effectiveness of various teaching practices.

to investigate relations between teaching methods and student learning in SoTL-type projects (Trigwell \& Prosser, 2004). The researchers believe that administering the TGI and ATI for future cohorts in this program will strengthen the results. The TGI will provide data that will determine a change in the teaching goals of the individual faculty scholar while the ATI will provide data to determine a change in teaching approaches for the particular class studied in the SoTL program. Both will provide results that can be shared with the broader community.

\section{Conclusions}

While there is much literature on the many benefits of the Scholarship of Teaching and Learning (SoTL) programs, there is scant literature about how participating in a SoTL program can impact faculty participants' teaching goals. This study was able to determine that faculty participants in an inaugural SoTL program reported that program participation reinvigorated their passion for teaching and allowed them to focus on improving student learning. By utilizing the Teaching Goals Inventory as a pre- and post-test measures, researchers were able to determine a teaching goal increase in two of the six clusters (cluster IV, Liberal Arts and Academic Value; cluster VI, Personal Development). SoTL provided faculty, using research language and methodology, a student-centered focus across disciplines igniting a university transformation to one of reflection and problem solving. SoTL brings the researcher mindset to the classroom. It is one way an educator can transform lackluster teaching techniques to reflection and evidence-based instruction to improve student learning. The SoTL experience has the capacity to influence faculty to value, thereby 
include, new approaches in their respective classrooms. This value and new thinking toward teaching and learning by faculty scholars could lead to the use of approaches that support students in becoming life-long learners who appreciate new ideas (i.e., TGI cluster IV). Faculty who use approaches to aid their students in the development of respect for colleagues and the understanding of the need to collaborate with peers (i.e., TGI cluster VI) to accomplish critical tasks and projects have the power to influence and impact higher education curriculum, regardless of the discipline.

\section{Acknowledgments}

The SoTL Program at Tarleton State University would not be possible without the generous support of the Provost and Academic Affairs.

\section{References}

Albornoz Pardo, C. (2013). Is business creation the mean or the end of entrepreneurship education? A multiple case study exploring teaching goals in entrepreneurship education. Journal of Technology Management \& Innovation, $8(1), 1-10$.

Angelo, T. A., \& Cross, K. P. (1993a). Classroom assessment techniques: $A$ handbook for college teachers. San Francisco: Jossey-Bass Inc.

Angelo, T. A., \& Cross, K. P. (1993b). Exhibit 2.1. Teaching goals inventory, self-scorable version. In Angelo, T. A., \& Cross, K. P. (Eds.) Classroom assessment techniques: A handbook for college teachers (pp. 20-21). San Francisco: Jossey-Bass Inc.

Bernstein, D. (2013). How SoTL-active faculty members can be cosmopolitan assets to an institution. Teaching and Learning Inquiry: The ISSOTL Journal, 1(1), 35-40. Indiana University Press. Retrieved from Project MUSE database.

Boyer, E. L. (1990). Scholarship reconsidered: Priorities of the professoriate. New York: Carnegie Foundation for the Advancement of Teaching.
Carnegie Foundation for the Advancement of Teaching. (2004) The CASTL survey. Retrieved from http://archive.carnegiefoundation.org/p dfs/tools-sharing/CASTL_survey.pdf

Case, K. A. (2013). Expanding the teaching commons: Making the case for a new perspective on SoTL. Insight: $A$ Journal of Scholarly Teaching, 8, 37-43.

Colorado Community College. (2018). Teaching goals inventory. Retrieved from https://www.ccconline.org/teachinggoals-inventory/

Condon, W., Iverson, E. R., Manduca, C. A., Rutz, C., \& Willett, G. (2016). Faculty development and student learning: Assessing the connections. Bloomington: Indiana University Press.

Cox, M. D. (2004). Introduction to faculty learning communities. New Directions for Teaching $\mathcal{E}$ Learning, 2004(97), 5-23.

Cross, K. P., \& California Univ., B. E. (2005). On college teaching. Research \& occasional paper series: CSHE.15.05. Center for Studies in Higher Education, Retrieved from https://files.eric.ed.gov/fulltext/ED4922 17.pdf 
De Winter, J. J. (2013). Using the Student's t-test with extremely small sample sizes. Practical Assessment, Research $\mathcal{E}$ Evaluation, 18(10), 1-12. Retrieved from

http://pareonline.net/getvn.asp?v=18\&n $=10$

Define Your Goals. (Winter, 1993). Speaking of teaching. Stanford University Newsletter on Teaching, 4(2), 1-4.

Dickson, K. L., \& Treml, M. M. (2013). Using assessment and SoTL to enhance student learning. New Directions for Teaching and Learning, 136, 7-26.

Donnelly, R. (2008). Lecturers' selfperception of change in their teaching approaches: reflections on a qualitative study. Educational Research, 50(3), 207222. doi: 10.1080/00131880802309317

Friedrichsen, P. M., \& Dana, T. M. (2005). Substantive-level theory of highly regarded secondary biology teachers' science teaching orientations. Journal of Research in Science Teaching, 42(2), 218244. doi:10.1002/tea.20046

Garza, J., Shaffer, K., Gentry, J., Maben, S., McGahan, D. (2014, January). Implementing a scholarship of teaching and learning (SoTL) faculty development initiative. Paper presented at the meeting of the Lilly Conference on College and University Teaching and Learning, Austin, TX.

Grossman, P. L. (1990). The making of a teacher: Teacher knowledge and teacher education. New York: Teachers College Press.

Hattie, J. A. C. (2009). Visible learning. Abingdon, UK: Routledge.
Hodges, L. C. (2013). Postcards from the edge of SoTL: A view from faculty development. Teaching and Learning Inquiry: The ISSOTL Journal 1(1), 71-79. Indiana University Press. Retrieved from Project MUSE database.

Hutchings, P., \& Shulman, L. (1999). The scholarship of teaching new elaborations, new developments. Change, 31(5), 11-15.

Johnson, L. D. (1997). Faculty teaching goals at senior research institutions (Doctoral dissertation). Retrieved from http://citeseerx.ist.psu.edu/viewdoc/do wnload?doi=10.1.1.2.9968\&rep=rep1\&ty pe=pdf

Kenny, N., \& Evers, F. (2010). Responding to the challenging dilemma of faculty engagement in research on teaching and learning and disciplinary research. Collected Essays on Learning and Teaching, 3, 21-26.

Kern, B., Mettetal, G., Dixson, M. D., \& Morgan, R. K. (2015). The role of SoTL in the academy: Upon the $25^{\text {th }}$ anniversary of Boyer's scholarship reconsidered. Journal of the Scholarship for Teaching and Learning, 15(3), 1-14.

Marcketti, S., VanDerZanden, A. M., \& Leptien, J. R. (2015). SoTL champions: Leveraging their lessons learned. International Journal for the Scholarship of Teaching and Learning, 9(1), Article 4.

Merriam, S. (2009). Qualitative research: A guide to design and implementation. San Francisco, CA: Jossey-Bass.

Myers, C. B. (2008). College faculty and the scholarship of teaching: Gender differences across four key activities. Journal of the Scholarship of Teaching and Learning, 8(2), 38-51. 
Nicholls, G. (2004). Scholarship in teaching as a core professional value: What does this mean to the academic? Teaching in Higher Education, 9, 29-42.

Ortiz, E. E. (2011). An analysis of middle school mathematics pre-service teachers' development of teaching goals. International Journal for Mathematics Teaching E Learning, 1-21.

Poole, G., \& Chick, N. (2015). Weaving SoTL into our everyday lives. Teaching $\mathcal{E}$ Learning Inquiry: The ISSOTL Journal, $3(1), \quad 1-2$ doi: 10.2979/teachlearninqu.3.1.1

Postareff, L., Lindblom-Ylänne, S., \& Nevgi, A. (2008). A follow-up study of the effect of pedagogical training on teaching in higher education. Higher Education, 1, 29-43.

Richardson, R. C., \& Miller, D. B. (2011). Predicting the use of learner-centered instructional methods by undergraduate social work faculty. Journal of Baccalaureate Social Work, 16(2), 115-130.

Science Education Resource Center at Carleton College. (n.d.). Teaching Goals Inventory. Retrieved from https://serc.carleton.edu/resources/2272 5.html

Sheskin, D. J. (2011). Handbook of parametric and nomparametric statistical procedures (5th ed.). Boca Raton, FL: Chapman \& Hall/CRC Press.

Simmons, N., Abrahamson, E., Deshler, J., Kensington-Miller, B., Manarin, K., Morón-García, S., ... Renc-Roe, J. (2013). Conflicts and configurations in a liminal space: SoTL scholars' identity development. Teaching $\mathcal{E}$ Learning Inquiry, $\quad$ 1(2), 9-21. http://dx.doi.org/10.20343/teachlearninq u.1.2.9
Stevenson, C. D., \& Harris, G. K. (2014). Instruments for characterizing instructors' teaching practices: A review. NACTA Journal, 58(2), 102-108.

Trigwell, K. (2013). Evidence of the impact of scholarship of teaching and learning purposes. Teaching and Learning Inquiry: The ISSOTL Journal, 1(1), 95-105.

Trigwell, K., \& Prosser, M. (2004). Development and use of the approaches to teaching inventory. Educational Psychology Review, 16(4), 409-424.

Trigwell, K., Rodriguez, K. C., \& Han, F. (2012). Assessing the impact of a university teaching development programme. Assessment and Evaluation In Higher Education, 37(4), 499-511.

University of Iowa (1993). Teaching Goals Inventory. In T. A. Angelo \& K. P. Cross, Classroom assessment techniques: $A$ handbook for college teachers. San Francisco: Jossey-Bass Inc. Retrieved from

https://fm.iowa.uiowa.edu/fmi/xsl/tgi/d ata_entry.xsl?-db=tgi_data\&-

lay=Layout01\&-view

Vanderbilt University Center for Teaching. (2018). Classroom assessment techniques. Retrieved from https://cft.vanderbilt.edu/guides-subpages/cats/

Voelker, D., \& Martin, R. (2013). Wisconsin teaching fellows \& scholars program assessment project: Final report. University of Wisconsin System, Office of Professional $\mathcal{E}$ Instructional Development. Retrieved from https://www.uwgb.edu/UWGBCMS/me dia/CATL/pdf/WTFSStudy2013.pdf 
Wang, H., Hall, N. C., Goetz, T., \& Frenzel, A. C. (2017). Teachers' goal orientations: Effects on classroom goal structures and emotions. British Journal of Educational Psychology, 87(1), 90-107. doi: 10.1111/bjep.12137

Waterman, M., Weber, J., Pracht, C., Conway, K., Kunz, D., Evans, B., \& Starrett, D. (2010). Preparing scholars of teaching and learning using a model of collaborative peer consulting and action research. International Journal of Teaching and Learning in Higher Education, 22(2), 140-155.
Weimer, M. (2007). Content knowledge: A barrier to teacher development. Teaching Professor, 21(9), 4-6.

West, J. (2013). Deep and lifelong learning: When theory and SoTL intersect. Journal of the Scholarship of Teaching and Learning, 13(4), 11-20.

Dr. Shaffer is the Director of the Center for Instructional Innovation for Tarleton State University where she directs faculty development and innovation in teaching, academic computing, and the Learning Management System (LMS) for the university. She is also an Assistant Professor for the college of education where she teaches graduate courses in educational media and technology. Dr. Shaffer has taught higher education technology courses for over ten years. She has presented at numerous conferences on educational technology and has authored two textbooks on the Microsoft Office Suite for the Mac.

Dr. James E. Gentry is a Professor with the College of Education at Tarleton State University and teaches both graduate and undergraduate classes within the Department of Curriculum and Instruction. He also serves as the Associate Director for the Center for Instructional Innovation at Tarleton State. Dr. Gentry has published children's books, research studies in national and international journals, and has authored several textbook chapters during his tenure at Tarleton. Dr. Gentry has supervised and supported faculty scholars' research efforts aiding faculty peers implementing self-reflective teaching and learning techniques and strategies.

Dr. Sarah Maben teaches in the Department of Communication Studies at Tarleton State University, where she teaches media writing and public relations. She is a co-director for the Texas Social Media Research Institute and editor of The Journal of Social Media in Society. 